\title{
Исследования энергетического спектра квазидвумерных структур HgTe/CdHgTe магнитотранспортными методами
}

\author{
М.В. Якунин ${ }^{1}$, С.М. Подгорных ${ }^{1}$, А.В. Суслов ${ }^{2}$, С.С. Криштопенко ${ }^{3}$, В. Jouault ${ }^{3}$, W. Desrat $^{3}$, F. Teppe ${ }^{3}$, \\ В.Н. Неверов ${ }^{1}$, М.Р. Попов ${ }^{1}$, Н.Н. Михайлов ${ }^{4}$, С.А. Дворецкий ${ }^{4}$ \\ ${ }^{1}$ Институт физики металлов им.М.Н.Михеева УрО РАН, Екатеринбург 620137, С.Ковалевской 18 \\ ${ }^{2}$ National High Magnetic Field Laboratory, Florida State University, 1800 East Paul Dirac Drive, \\ Tallahassee, Florida 32310, USA \\ ${ }^{3}$ Laboratoire Charles Coulomb, UMR 5221 Centre National de la Recherché Scientifique, \\ University of Montpellier, F-34095 Montpellier, France \\ ${ }^{4}$ Институт физики полупроводников им. А.В. Ржанова СО РАН, Новосибирск 630090, \\ пр. Лаврентьева 13 \\ тел: +7 (343) 378-3644, эл. почта: yakunin@imp.uran.ru
}

DOI $10.34077 /$ RCSP2021-20

Представлены результаты исследований специфики энергетического спектра гетероструктур на основе $\mathrm{HgTe}$, характеризуемого инверсным расположением зон, образованных $s$-орбиталями (состояния типа $E$ ), и зон, сформированной $p$-орбиталями (состояния типа $H$ ), при толщинах слоев $\mathrm{HgTe}$, близких к критической величине в 6.3 нм, и более.

При больших толщинах слоя $\mathrm{HgTe}$ зона проводимости формируется состояниями типа $H$ (как и валентная зона), поэтому она характеризуется большим $g$-фактором, который к тому же анизотропен, то есть в наклонных полях величина спиновых расщеплений определяется не только полной величиной поля, но и соотношением его перпендикулярной слою и параллельной компонент. Представлены исследования анизотропии $g$-фактора зоны проводимости слоя $\mathrm{HgTe}$ толщиной 20 нм, а также возникающих вследствие обменного взаимодействия антипересечений уровней Ландау [1].

Простейшим вариантом многослойной системы является двойная квантовая яма (ДКЯ), состоящая из двух квазидвумерных слоев $\mathrm{HgTe}$, разделенных тонким барьером $\mathrm{Cd}_{x} \mathrm{Hg}_{1-x} \mathrm{Te}$, и окруженная таким же материалом. Если слои $\mathrm{HgTe}$ достаточно толстые (20 нм у нас), то актуальные состояния формируются в основном тяжелыми дырками (состояния $H$ ), для которых интенсивность туннелирования через барьер невелика. Поэтому общий спектр формируется наложением спектров отдельных слоев, возможно с их взаимным смещением по энергии, с некоторым влиянием формирующихся по периметру топологических состояний. В таких системах можно регулировать степень перекрытия зон проводимости и валентной, изменяя профиль ДКЯ приложением напряжения к нанесенному на поверхность затвору [2]. Этим регулируется соотношение между электронами и дырками в системе.

Самые необычные спектры формируются в ДКЯ при толщине слоев $\mathrm{HgTe}$, близкой к критической (от 6.5 до 8.5 нм в наших экспериментах). В этом случае актуальными являются не только состояния типа $H$, но и состояния $E$, для которых туннельная связь между слоями велика, что качественно преобразует весь спектр. В результате образуются весьма экзотические варианты коллективного спектра от аналога двуслойного графена (при 6.5 нм) до спектра с очень узкой щелью (для 8.5 нм), чувствительной к внешним воздействиям. Экспериментально показано [3], что из-за наложения серий уровней Ландау типа $H$ и $E$ может наблюдаться нетрадиционная возвратная картина квантового эффекта Холла, из которой можно анализировать характер состояний на уровнях - электронный или дырочный, а также определить детали профиля потенциала ДКЯ, оценить наличие антипересечений между уровнями. Формирующиеся боковые максимумы в подзонах энергетического спектра позволяют исследовать проблему резервуара малоподвижных носителей тока в сочетании с высокоподвижными в центральных экстремумах зон. В структурах с узкой щелью показано, что параллельное слоям магнитное поле способно таким образом влиять на энергетический спектр, что изменяется тип высокоподвижных носителей с дырок на электроны.

Исследования поддержаны грантом Министерства науки и высшего образования № 075-152020-797 (13.1902.21.0024).

\section{Лumepamypa}

[1] M.V. Yakunin et al., Phys. Rev. B. 2012. V.85. 245321.

[2] M.V. Yakunin et al., Phys. Rev. B. 2016. V.93. 085308.

[3] M.V. Yakunin et al., JETP Letters. 2016. V.104. P.403-410; Phys. Rev. B. 2020. V.102. 165305. 